\title{
Measuring the ICT Maturity of Enterprises under Uncertainty Using Group Fuzzy ANP
}

\author{
Pham Xuan Kien, Le Ngoc Son, and Nguyen Thi Phuong Giang
}

\begin{abstract}
Generally, measuring the Information and Communication Technology (ICT) maturity is the first step to build a new knowledge system in an enterprise. Knowing their ICT maturity also helps enterprises make a plan for improving the ICT state to strengthen their competitive capability. In this paper, the ICT maturity is based on four main factors: Infrastructure, Application, Human Resource and Policy. The concept of fuzzy set is applied to Analytic Network Process (ANP) to propose a model for measuring enterprise's ICT maturity under uncertain environment. Using group fuzzy ANP approach helps determine more efficiently importance weights of factors and indicators, especially deal with imprecise and uncertain human comparison judgments. A case study is used to illustrate the better new method of ICT maturity measurement.
\end{abstract}

Index Terms-Fuzzy logic, ANP, ICT maturity.

\section{INTRODUCTION}

In the era of information and knowledge, knowledge is one the most important factors for success. Knowledge has become an essential resource that organizations need to manage effectively to get their competitive advantage and develop steadily. Obviously, the knowledge management in organizations depends mostly on the development of Information and Communication Technology (ICT) [1]. With the very fast development of technology, most enterprises wonder what kind of ICT system is suitable for them and how to apply effectively ICT to improve their business. Only knowing their current state of ICT use, the enterprises could decide this question.

To measure the ICT maturity, we have to know the importance weights of each factor and their indicators. Therefore, an analytic Network Process (ANP) is used for determining the weights due to the fact that this method has been widely used in dealing with various kinds of MCDM problems. In addition, the uncertainty on judgments of many decision-makers exists and the conventional ANP cannot reflect the human thinking style yet. That is why a group fuzzy ANP approach is introduced to make up for that deficiency in determining the factor weights.

The following parts of paper consist: Session II defines ICT maturity and introduces a measurement for it. In Session III, the review on fuzzy ANP approach will be given. Session IV proposes a model to measure enterprise ICT maturity using group fuzzy ANP. An illustrative example is presented in Session V. The paper will be ended by conclusion part.

Manuscript received September 19, 2013; revised November 22, 2013.

The authors are with University of Electronic Science and Technology of China, Chengdu, 610054, China (e-mail: pxkien@yahoo.com, lengocsonit@gmail.com,phuonggiang1179@gmail.com).

\section{DEFINITION, Model, MEASUREMENT OF ICT MATURITY}

\section{A. Definition and Model}

ICT maturity of an enterprise is the state of an enterprise when it achieves the full development state in using ICT to support its business. In other words, the ICT maturity level shows how well an enterprise's ICT use is [2]. In order to determine the current maturity state of ICT use in an enterprise, it is required to carry out measuring the ICT maturity of that enterprise. Following is the model to measure ICT maturity of an enterprise proposed by Pham [3]. There are four main ICT factors inside an enterprise: ICT Policy, ICT Infrastructure, ICT Application and ICT Human Resource.

- ICT Policy: regulars or procedures of using ICT in an enterprise to benefit their business efficiency.

- ICT Infrastructure: devices and services, such as server, PC, laptop... This infrastructure is to store, process and communicate information.

- ICT Application: applications that support an enterprise doing its business.

- ICT Human Resource: staff literacy, skills, IT experts, IT leaders, ICT training, R\&D activities...

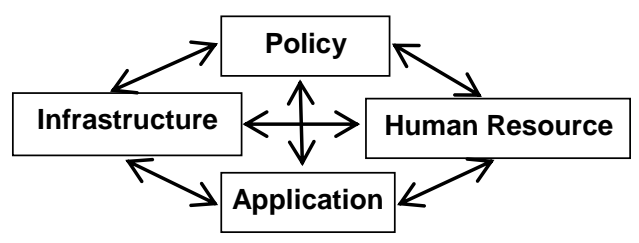

Fig. 1. Model of ICT maturity in an enterprise.

M. Chesser \& W. Skok [4] and Pham [3] suggested the 5-stage road map of ICT develop to determine the level of ICT maturity.

- $\quad$ Stage 1: Inactive - no current use of ICT in company

- Stage 2: Basic - including word processing and other desktop packages

- $\quad$ Stage 3: Substantial - extending into the networking of PCs and applications

- $\quad$ Stage 4: Web-based - extending to e-commerce with many web-based services.

- Stage 5: Knowledge-oriented - integration of applications and using ICT tools for innovation and knowledge management.

Each of ICT maturity levels is characterized by major ICT factors: Policy, Infrastructure, Application and Human Resource. The measure of ICT maturity needs to collect all data about ICT usage according to 4 major factors. 


\section{B. Measurement for ICT Maturity}

This paper will use the measurement proposed by Pham, see Table I. The column 'Stage' combines indicators with development stages. The ICT maturity index (ICTMI) will be calculated by following formula:

$$
\begin{gathered}
I C T M I=\alpha I+\beta A+\gamma H+\theta P \\
(0 \leq I, A, H, P, I C T M I \leq 1, \alpha+\beta+\gamma+\theta=1)
\end{gathered}
$$

In his paper, Pham did not mention group of decision makers as well as uncertainty in their judgments. Pham let the weights of $I, A, H, P$ as $\alpha=\beta=\gamma=\theta=1 / 4$. After calculation, the obtained ICTMI can be mapped to 5 stages of ICT development road-map by the rule: 0-1/5: Inactive; 1/5-2/5: Basic; 2/5-3/5: Substantial; 3/5-4/5: Web-based; 4/5-1: Knowledge-oriented. This paper will use the group fuzzy ANP approach to determine more appropriate coefficients for $I, A, H$ and $P$ in untertain environment to get

\begin{tabular}{|c|c|c|}
\hline Factor & Indicator & Stage \\
\hline \multirow{11}{*}{ 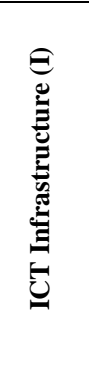 } & Fixed telephones & 2 \\
\hline & Mobile devices & 5 \\
\hline & Number of computers & 2 \\
\hline & Type of internet access & 4 \\
\hline & Local network & 3 \\
\hline & Internet bandwidth & 4 \\
\hline & Secure internet server/ Hosting & 4 \\
\hline & Security \& backup system & 4 \\
\hline & Wide area network (WAN/ GAN) & 3 \\
\hline & Wireless LAN/ Wifi & 5 \\
\hline & WAP access & 5 \\
\hline \multirow{14}{*}{ 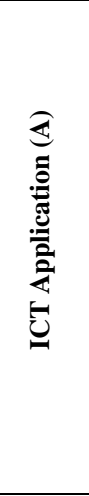 } & Standard application software & 2 \\
\hline & Internet use for getting information & 4 \\
\hline & Website & 4 \\
\hline & Service for which internet is used & 4 \\
\hline & Value of online purchases & 4 \\
\hline & Value of online sales & 4 \\
\hline & E-marketing & 5 \\
\hline & E-mail/ IM for communicating & 2 \\
\hline & Social network for cooperate & 5 \\
\hline & Remote meeting/ video conference & 5 \\
\hline & Intranet/ Extranet & 3 \\
\hline & Management information systems & 3 \\
\hline & SCM/ ERP/ CRM & 3 \\
\hline & Business intelligent/ Knowledge Base & 5 \\
\hline \multirow{10}{*}{ 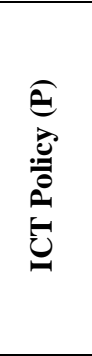 } & ICT investment & 3 \\
\hline & Quality policy & 2 \\
\hline & Privacy policy & 4 \\
\hline & Regulatory policy & 2 \\
\hline & Security policy & 4 \\
\hline & Piracy policy & 5 \\
\hline & IT expert recruitment/ training & 5 \\
\hline & Upgrade ICT hardware/ software & 3 \\
\hline & Assessment effectiveness & 5 \\
\hline & ICT use for KM is a priority & 5 \\
\hline \multirow{12}{*}{ 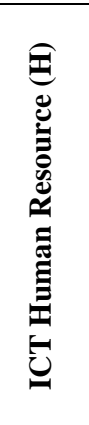 } & ICT training & 3 \\
\hline & Share of employee using a computer & 2 \\
\hline & Share of employee using the internet & 4 \\
\hline & Royalty payment \& receipt & 5 \\
\hline & Patent application & 5 \\
\hline & Company spending on R\&D & 5 \\
\hline & Capacity for innovation & 5 \\
\hline & IT specified employee & 3 \\
\hline & IT department/ CIO & 4 \\
\hline & Business specified employee & 2 \\
\hline & Self-learning skill & 5 \\
\hline & Expertise reuse & 5 \\
\hline
\end{tabular}
a better ICT maturity index.

\section{BASIC CONCEPT OF FUZZY ANP}

- Triangular fuzzy number

A fuzzy number $\tilde{M}$ on R to be a triangular fuzzy number if its membership function: $\mu_{\tilde{M}}(x): R \rightarrow[0,1]$ is

$$
\mu_{\tilde{M}}(x)= \begin{cases}\frac{x-l}{m-l} & l \leq x \leq m \\ \frac{u-x}{u-m} & m \leq x \leq u \\ 0 & \text { otherwise }\end{cases}
$$

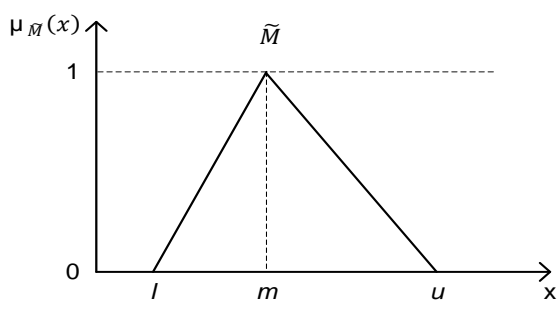

Fig. 2. A triangular fuzzy number.

Fig. 2. represents the triangular fuzzy number.

Consider two triangular fuzzy numbers $\tilde{M}_{1}$ and $\tilde{M}_{2}$, $\tilde{M}_{1}=\left(l_{1}, m_{1}, u_{1}\right)$ and $\tilde{M}_{2}=\left(l_{2}, m_{2}, u_{2}\right)$.

The basic operations:

$$
\begin{gathered}
\tilde{M}_{1} \oplus \tilde{M}_{2}=\left(l_{1}+l_{2}, m_{1}+m_{2}, u_{1}+u_{2}\right) \\
\tilde{M}_{1} \otimes \tilde{M}_{2} \approx\left(l_{1} l_{2}, m_{1} m_{2}, u_{1} u_{2}\right) \\
\tilde{M}_{1}^{-1}=\left(\frac{1}{u_{1}}, \frac{1}{m_{1}}, \frac{1}{l_{1}}\right)
\end{gathered}
$$

The fuzzy extent AHP approach was proposed by Chang [5]. Let $X=\left\{x_{1}, x_{2}, \ldots, x_{n}\right\}$ be an object set, and $G=\left\{g_{1}, g_{2}, \ldots, g_{n}\right\}$ be a goal set. According to the method of Chang's extent analysis, each object is taken and extent analysis for each goal $\mathrm{g}_{\mathrm{i}}$, is performed respectively.

Therefore, $m$ extent analysis values for each object can be obtained, with the following signs: $\tilde{M}_{g_{1}}^{1}, \tilde{M}_{g_{1}}^{2}, \ldots, \tilde{M}_{g_{1}}^{m}$, where all the $\tilde{M}_{g_{1}}^{j}(j=1,2, \ldots, m)$ are triangular fuzzy numbers. The steps of Chang's extent analysis can be given as follows:

- $\quad$ The degree of possibility of $\tilde{M}_{1}=\left(l_{1}, m_{1}, u_{1}\right) \geq$ $\tilde{M}_{2}=\left(l_{2}, m_{2}, u_{2}\right)$ is defined as following (see Fig. 3.):

$$
V\left(\tilde{M}_{1} \geq \tilde{M}_{2}\right)=\left\{\begin{array}{lc}
1 & m_{1} \geq m_{2} \\
\frac{l_{2}-u_{1}}{\left(m_{1}-u_{1}\right)-\left(m_{2}-l_{2}\right)} & m_{1}<m_{2}, u_{1} \geq l_{2} \\
0 & \text { otherwise }
\end{array}\right.
$$

- The value of fuzzy synthetic extent with respect to the $\mathrm{i}^{\text {th }}$ object is defined as:

$$
\tilde{S}_{i}=\sum_{j=1}^{m} \tilde{M}_{g_{i}}^{j} \otimes\left[\sum_{i=1}^{n} \sum_{j=1}^{m} \tilde{M}_{g_{i}}^{j}\right]^{-1}
$$

where

$$
\sum_{j=1}^{m} \tilde{M}_{g_{i}}^{j}=\left(\sum_{j=1}^{m} l_{j}, \sum_{j=1}^{m} m_{j}, \sum_{j=1}^{m} u_{j}\right)
$$




$$
\begin{gathered}
\sum_{i=1}^{n} \sum_{j=1}^{m} \tilde{M}_{g_{i}}^{j}=\left(\sum_{i=1}^{n} l_{i}, \sum_{i=1}^{n} m_{i}, \sum_{i=1}^{n} u_{i}\right) \\
{\left[\sum_{i=1}^{n} \sum_{j=1}^{m} \tilde{M}_{g_{i}}^{j}\right]^{-1}=\left(\frac{1}{\sum_{i=1}^{n} u_{i}}, \frac{1}{\sum_{i=1}^{n} m_{i}}, \frac{1}{\sum_{i=1}^{n} l_{i}}\right)}
\end{gathered}
$$

- The degree possibility for a convex fuzzy number to be greater than k convex fuzzy numbers $\tilde{M}_{i} \mathrm{i}=(1$, $2, \ldots, k)$ can be defined by:

$$
V\left(\tilde{M} \geq \tilde{M}_{1}, \tilde{M}_{2}, \ldots, \tilde{M}_{k}\right)=\min _{i=1,2, \ldots, k} V\left(\tilde{M} \geq \tilde{M}_{i}\right)
$$

Assume that $d^{\prime}\left(A_{i}\right)=V\left(\tilde{S}_{i} \geq \tilde{S}_{k}\right)$ then the weight vector is given as:

$$
W^{\prime}=\left[d^{\prime}\left(A_{1}\right), d^{\prime}\left(A_{2}\right), \ldots, d^{\prime}\left(A_{n}\right)\right]^{T}
$$

where $A_{i}(\mathrm{i}=1,2, \ldots, n)$ are n elements.

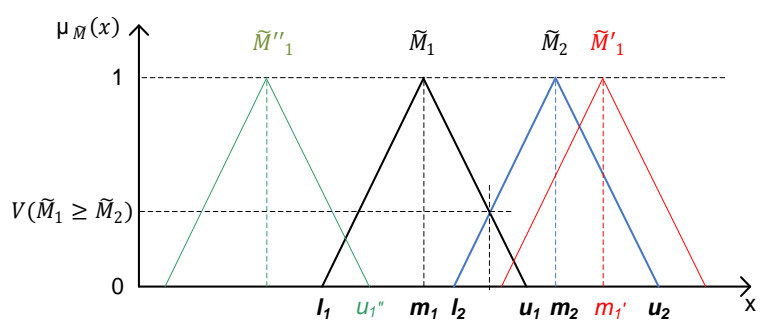

Fig. 3. Degree of possibility of $\tilde{M}_{1}=\left(l_{1}, m_{1}, u_{1}\right) \geq \tilde{M}_{2}=\left(l_{2}, m_{2}, u_{2}\right)$.

- $\quad$ Normalize the weight vectors:

$$
W=\left[d\left(A_{1}\right), d\left(A_{2}\right), \ldots, d\left(A_{n}\right)\right]^{T}
$$

\section{THE Proposed MOdEL FOR MEASURING ICTMI}

The group fuzzy ANP method [6] is applied in this model to measure an enterprise's ICT maturity. The process of measurement includes following steps:

Step 1: Define measuring factors and linguistic variables.

Firstly, define measuring factors. As presented above, the measurement of ICT maturity consists of 4 main factors. Each factor has its own indicators: 11 indicators for Infrastructure (I), 14 indicators for Application (A), 12 indicators for Human resource $(\mathrm{H})$ and 10 indicators for Policy (P).

Then, define the appropriate linguistic variables for the importance weight of factors and indicators. This paper suggests linguistic terms that can be expressed in positive triangular fuzzy numbers. See Table II.

TABLE II: LINGUISTIC VARIABLES FOR IMPORTANT WEIGHT.

\begin{tabular}{|c|l|c|}
\hline \multicolumn{2}{|c|}{ Linguistic terms } & Linguistic value \\
\hline JEP & Just equally preferred & $(1,1,1)$ \\
\hline WMP & Weak more preferred & $(1 / 2,1,3 / 2)$ \\
\hline MMP & Moderately more preferred & $(1,3 / 2,2)$ \\
\hline SMP & Strongly more preferred & $(3 / 2,2,5 / 2)$ \\
\hline VMP & Very strongly more preferred & $(2,5 / 2,3)$ \\
\hline AMP & Absolutely more preferred & $(5 / 2,3,7 / 2)$ \\
\hline
\end{tabular}

Step 2: Determine the weight vector of factors and indicators.

Firstly, collect judgments in term of linguistic variable from a group of experts then create pairwise comparison matrices. Calculate consistency index (CI) and consistency ratio $(\mathrm{CR})$ to determine the consistency level from each expert. Use formula (3) and take the average values to obtain the combined comparison matrix for whole group of experts.

The local weight vector of factors is determined by using formulas (6) to (12). Then it is normalized by using formula (13). Next, develop the dependent matrix of factors from inner dependent matrices with respect to each factor. The interdependent weight of factors is derived from local weight vector and dependent matrix of factor. The importance weights of indicators can be calculated in the same method above.

Step 3: Calculate the ICTMI.

Use formula (1) to calculate the ICTMI.

\section{ILlUSTRATIVE EXAMPLE (CASE STUdY)}

The following example demonstrates the applying proposed method to calculate the ICTMI. A group of 3 experts had convened to measure the ICTMI of an enterprise. They used a questionnaire based on indicators (Table I) to collect data. To measure ICTMI, they must have importance weights of 4 main factors and their indicators. TABLE III (A) shows the pairwise comparison matrix made from 3 expert's judgments using linguistic terms in Table II.

Firstly, it is necessary to test the consistency of each expert judgment. We have 3 different experts. The consistency test results are: $\mathrm{CI}_{1}=0.0711, \mathrm{CR}_{1}=0.0799<0.1$; $\mathrm{CI}_{2}=0.0629, \quad \mathrm{CR}_{2}=0.0706<0.1 ; \quad \mathrm{CI}_{3}=0.0542$, $\mathrm{CR}_{3}=0.0609<0.1$ so all of 3 expert's judgments successfully pass the consistency test. Use formula (3) and take the average values, we obtain the combined pairwise comparison matrix in Table III (B).

TABLE III (A): PAIRWISE COMPARISON MATRIX OF FACTORS

\begin{tabular}{|l|l|l|l|l|}
\hline \multirow{4}{*}{$\mathbf{I}$} & I & A & H & $\mathbf{P}$ \\
\hline \multirow{4}{*}{$\mathbf{A}$} & JEP & MMP & SMP & WMP \\
\cline { 2 - 5 } & JEP & SMP & SMP & WMP \\
\cline { 2 - 5 } & JEP & VSP & SMP & MMP \\
\hline \multirow{4}{*}{$\mathbf{H}$} & & JEP & MMP & SMP \\
\hline & & JEP & MMP & SMP \\
\cline { 2 - 5 } & & JEP & MMP & VMP \\
\hline & & & JEP & MMP \\
\hline \multirow{3}{*}{$\mathbf{P}$} & & & JEP & MMP \\
\cline { 2 - 5 } & & & JEP & MMP \\
\cline { 2 - 5 } & & & & JEP \\
\hline
\end{tabular}

TABLE III (B): COMBINED MATRIX OF EXPERT GROUP

\begin{tabular}{|l|l|l|l|l|}
\hline & $\mathbf{I}$ & $\mathbf{A}$ & $\mathbf{H}$ & $\mathbf{P}$ \\
\hline $\mathbf{I}$ & $(1,1,1)$ & $(3 / 2,2,5 / 2)$ & $(3 / 2,2,5 / 2)$ & $(2 / 3,7 / 6,5 / 3)$ \\
\hline $\mathbf{A}$ & $(2 / 5,1 / 2,2 / 3)$ & $(1,1,1)$ & $(1,3 / 2,2)$ & $(5 / 3,13 / 6,8 / 3)$ \\
\hline $\mathbf{H}$ & $(2 / 5,1 / 2,2 / 3)$ & $(1 / 2,2 / 3,1)$ & $(1,1,1)$ & $(1,3 / 2,2)$ \\
\hline $\mathbf{P}$ & $(3 / 5,6 / 7,3 / 2)$ & $(3 / 8,6 / 13,3 / 5)$ & $(1 / 2,2 / 3,1)$ & $(1,1,1)$ \\
\hline
\end{tabular}


Then apply formulas (7) to (10) to calculate the fuzzy synthetic extent values:

$$
\begin{aligned}
& \tilde{S}_{I}=(0.205,0.343,0.543), \tilde{S}_{A}=(0.179,0.287,0.449) \\
& \tilde{S}_{H}=(0.127,0.204,0.331), \tilde{S}_{P}=(0.109,0.160,0.291)
\end{aligned}
$$

Use formula (11) to calculate:

$$
\begin{aligned}
& V\left(\tilde{S}_{I} \geq \tilde{S}_{A}\right)=1.000, V\left(\tilde{S}_{I} \geq \tilde{S}_{H}\right)=1.000, V\left(\tilde{S}_{I} \geq \tilde{S}_{P}\right)=1.000 \\
& V\left(\tilde{S}_{A} \geq \tilde{S}_{I}\right)=0.814, V\left(\tilde{S}_{A} \geq \tilde{S}_{H}\right)=1.000, V\left(\tilde{S}_{A} \geq \tilde{S}_{P}\right)=1.000 \\
& V\left(\tilde{S}_{H} \geq \tilde{S}_{I}\right)=0.475, V\left(\tilde{S}_{H} \geq \tilde{S}_{A}\right)=0.646, V\left(\tilde{S}_{H} \geq \tilde{S}_{P}\right)=1.000 \\
& V\left(\tilde{S}_{P} \geq \tilde{S}_{I}\right)=0.326, V\left(\tilde{S}_{P} \geq \tilde{S}_{A}\right)=0.480, V\left(\tilde{S}_{P} \geq \tilde{S}_{H}\right)=0.812
\end{aligned}
$$

Then, use formula (12), (13) to calculate the local weight vector of factors:

$$
d^{\prime}(I)=1.000, d^{\prime}(A)=0.814, d^{\prime}(H)=0.475, d^{\prime}(P)=0.326
$$

Therefore, the weight vector is

$$
W^{\prime}=(1.000,0.814,0.475,0.326)^{T}
$$

Via normalization, we obtain the local weight vector of 4 main factors:

$$
W=(0.382,0.311,0.182,0.125)^{T}
$$

It's turn to calculate the independent weight of main factors. At first, consider the inner dependent matrix with respect to each of 4 main factors.

TABLE IV (A): PAIRWISE COMPARISON MATRIX OF FACTORS WITH

RESPECT TO INFRASTRUCTURE (I)
\begin{tabular}{|c|c|c|c|}
\hline $\mathbf{I}$ & $\mathbf{A}$ & $\mathbf{H}$ & $\mathbf{P}$ \\
\hline \multirow{3}{*}{$\mathbf{A}$} & JEP & SMP & MMP \\
\cline { 2 - 4 } & JEP & VMP & SMP \\
\cline { 2 - 4 } & JEP & AMP & SMP \\
\hline \multirow{3}{*}{$\mathbf{H}$} & & JEP & WMP \\
\cline { 2 - 4 } & & JEP & WMP \\
\cline { 2 - 4 } & & JEP & MMP \\
\hline \multirow{2}{*}{$\mathbf{P}$} & & & JEP \\
\cline { 2 - 4 } & & & JEP \\
\cline { 2 - 4 } & & & JEP \\
\hline
\end{tabular}

TABLE IV (B): COMBINED COMPARISON MATRIX OF FACTORS WITH RESPECT TO INFRASTRUCTURE (I)

\begin{tabular}{|c|c|c|c|}
\hline $\mathbf{I}$ & $\mathbf{A}$ & $\mathbf{H}$ & $\mathbf{P}$ \\
\hline $\mathbf{A}$ & $(1,1,1)$ & $(2,5 / 2,3)$ & $(4 / 3,11 / 6,7 / 3)$ \\
\hline $\mathbf{H}$ & $(1 / 3,2 / 5,1 / 2)$ & $(1,1,1)$ & $(2 / 3,7 / 6,5 / 3)$ \\
\hline $\mathbf{P}$ & $(3 / 7,6 / 11,3 / 4)$ & $(3 / 5,6 / 7,3 / 2)$ & $(1,1,1)$ \\
\hline
\end{tabular}

Applying the same method above that used to calculate the local weight vector of 4 main factors $\mathrm{W}$, with TABLE IV(A) \& TABLE IV(B), we have the vector of factor weight in respect to Infrastructure (I) $W_{I}=[0.786,0.099,0.115]$

Let's consider 3 other inner dependent matrices:

TABLE V (A): PAIRWISE COMPARISON MATRIX OF FACTORS WITH

\begin{tabular}{|c|c|c|c|}
\multicolumn{4}{c|}{ RESPECT TO APPLICATION (A) } \\
\hline $\mathbf{A}$ & $\mathbf{I}$ & $\mathbf{H}$ & $\mathbf{P}$ \\
\hline \multirow{3}{*}{$\mathbf{I}$} & JEP & WMP & MMP \\
\cline { 2 - 4 } & JEP & MMP & SMP \\
\cline { 2 - 4 } & JEP & WMP & VMP \\
\hline \multirow{3}{*}{$\mathbf{H}$} & & JEP & MMP \\
\cline { 2 - 4 } & & JEP & MMP \\
\cline { 2 - 4 } & & JEP & SMP \\
\hline \multirow{3}{*}{$\mathbf{P}$} & & & JEP \\
\cline { 2 - 4 } & & & JEP \\
\cline { 2 - 4 } & & & JEP \\
\hline
\end{tabular}

TABLE V (B): COMBINED COMPARISON MATRIX OF FACTORS WITH RESPECT TO APPLICATION (A)

\begin{tabular}{|c|c|c|c|}
\hline $\mathbf{A}$ & $\mathbf{I}$ & $\mathbf{H}$ & $\mathbf{P}$ \\
\hline $\mathbf{I}$ & $(1,1,1)$ & $(2 / 3,7 / 6,5 / 3)$ & $(3 / 2,2,5 / 2)$ \\
\hline $\mathbf{H}$ & $(5 / 3,6 / 7,3 / 2)$ & $(1,1,1)$ & $(7 / 6,5 / 3,13 / 6)$ \\
\hline $\mathbf{P}$ & $(2 / 5,1 / 2,2 / 3)$ & $(6 / 13,3 / 5,6 / 7)$ & $(1,1,1)$ \\
\hline
\end{tabular}

We have result $W_{A}=[0.480,0.403,0.116]$

TABLE VI (A): PAIRWISE COMPARISON MATRIX OF FACTORS WITH

RESPECT TO HUMAN RESOURCE $(\mathrm{H})$
\begin{tabular}{|c|c|c|c|}
\hline $\mathbf{H}$ & $\mathbf{I}$ & $\mathbf{A}$ & $\mathbf{P}$ \\
\hline \multirow{3}{*}{$\mathbf{I}$} & JEP & MMP & WMP \\
\cline { 2 - 4 } & JEP & MMP & WMP \\
\cline { 2 - 4 } & JEP & WMP & MMP \\
\hline \multirow{3}{*}{$\mathbf{A}$} & & JEP & WMP \\
\cline { 2 - 4 } & & JEP & WMP \\
\cline { 2 - 4 } & & JEP & WMP \\
\hline \multirow{2}{*}{$\mathbf{P}$} & & & JEP \\
\cline { 2 - 4 } & & & JEP \\
\cline { 2 - 4 } & & & JEP \\
\hline
\end{tabular}

TABLE VI (B): COMBINED COMPARISON MATRIX OF FACTORS WITH RESPECT TO HUMAN RESOURCE $(\mathrm{H})$

\begin{tabular}{|c|c|c|c|}
\hline $\mathbf{H}$ & $\mathbf{I}$ & $\mathbf{A}$ & $\mathbf{P}$ \\
\hline $\mathbf{I}$ & $(1,1,1)$ & $(5 / 6,4 / 3,11 / 6)$ & $(2 / 3,7 / 6,5 / 3)$ \\
\hline $\mathbf{A}$ & $(6 / 11,3 / 4,6 / 5)$ & $(1,1,1)$ & $(1 / 2,1,3 / 2)$ \\
\hline $\mathbf{P}$ & $(3 / 5,6 / 7,3 / 2)$ & $(2 / 3,1,2)$ & $(1,1,1)$ \\
\hline
\end{tabular}

The vector of factor weight in respect to Human resource (H) is

$$
W_{H}=[0.374,0.302,0.324]
$$

TABLE VII (A): PAIRWISE COMPARISON MATRIX OF FACTORS WITH

\begin{tabular}{|c|c|c|c|}
\hline \multicolumn{1}{|c|}{ RESPECT TO POLICY (P) } \\
\hline $\mathbf{P}$ & $\mathbf{I}$ & $\mathbf{A}$ & $\mathbf{H}$ \\
\hline \multirow{3}{*}{$\mathbf{I}$} & JEP & $1 /$ SMP & MMP \\
\cline { 2 - 4 } & JEP & $1 /$ SMP & MMP \\
\cline { 2 - 4 } & JEP & $1 /$ SMP & MMP \\
\hline \multirow{3}{*}{$\mathbf{A}$} & & JEP & MMP \\
\cline { 2 - 4 } & & JEP & SMP \\
\cline { 2 - 4 } & & JEP & SMP \\
\hline \multirow{3}{*}{$\mathbf{H}$} & & & JEP \\
\cline { 2 - 4 } & & & JEP \\
\cline { 2 - 4 } & & & JEP \\
\hline
\end{tabular}

TABLE VII (B): COMBINED COMPARISON MATRIX OF FACTORS WITH

\begin{tabular}{|c|c|c|c|}
\hline $\mathbf{P}$ & $\mathbf{I}$ & $\mathbf{A}$ & $\mathbf{H}$ \\
\hline $\mathbf{I}$ & $(1,1,1)$ & $(2 / 5,1 / 2,2 / 3)$ & $(1,3 / 2,2)$ \\
\hline $\mathbf{A}$ & $(3 / 2,2,5 / 2)$ & $(1,1,1)$ & $(4 / 3,11 / 6,7 / 3)$ \\
\hline $\mathbf{H}$ & $(1 / 2,2 / 3,1)$ & $(3 / 7,6 / 11,3 / 4)$ & $(1,1,1)$ \\
\hline
\end{tabular}

The vector of factor weight in respect to Policy $(\mathrm{P})$ is

$$
W_{P}=[0.283,0.661,0.056]
$$

The independent weights of factors are calculated by multiplying the dependent matrix of factors with the local weights of factors as follow

$\left[\begin{array}{llll}1.000 & 0.480 & 0.374 & 0.283 \\ 0.786 & 1.000 & 0.302 & 0.661 \\ 0.099 & 0.403 & 1.000 & 0.056 \\ 0.115 & 0.116 & 0.324 & 1.000\end{array}\right] \times\left[\begin{array}{l}0.382 \\ 0.311 \\ 0.182 \\ 0.125\end{array}\right]=\left[\begin{array}{l}0.635 \\ 0.749 \\ 0.352 \\ 0.264\end{array}\right]$


TABLE VIII: FACTORS AND ITS INDICATOR'S WEIGHT

\begin{tabular}{|l|l|l|}
\hline Factors & Local weights & Global weights \\
\hline I - Infrastructure & & $\mathbf{0 . 3 1 8}$ \\
\hline Fixed telephones & 0.085 & 0.027030 \\
\hline Mobile devices & 0.105 & 0.033390 \\
\hline Number of computers & 0.114 & 0.036252 \\
\hline Type of internet access & 0.076 & 0.024168 \\
\hline Local network & 0.049 & 0.015582 \\
\hline Internet bandwidth & 0.098 & 0.031164 \\
\hline Secure internet server & 0.032 & 0.010176 \\
\hline Security \& backup system & 0.024 & 0.007632 \\
\hline Wide area network & 0.183 & 0.058194 \\
\hline Wireless LAN/ Wifi & 0.179 & 0.056922 \\
\hline WAP access & 0.055 & 0.017490 \\
\hline A - Application & & $\mathbf{0 . 3 7 5}$ \\
\hline H - Human resource & & $\mathbf{0 . 1 7 6}$ \\
\hline P - Policy & & $\mathbf{0 . 1 3 2}$ \\
\hline
\end{tabular}

The result of operation is $[0.635,0.749,0.352,0.264]$.

By normalization, $W=[0.318,0.375,0.176,0.132]^{T}$.

Applying the same way, we also can calculate the local and global weights of indicators. As a result, TABLE VIII shows the importance weight of ICT Infrastructure factor and its indicators.

\section{CONCLUSION}

This paper contributes to an aspect of building a knowledge system by doing the very beginning step. That is measuring the ICT maturity level in an enterprise. The model of ICT maturity used includes 4 main factors ICT policy, ICT infrastructure, ICT application and ICT human resource. A group fuzzy ANP approach is used to determine efficiently important weight of each factor or indicator to ICT maturity. The proposed model using fuzzy set helps to deal with imprecise and uncertain human comparison judgments. The group approach also helps get more effective in assessment by collect judgments from many experts, not only one expert. With the obtained result, the enterprise can evaluate their current ICT maturity, so that they make a plan to improve their ICT state.

\section{ACKNOWLEDGMENT}

We would like to thank Professor Kou Gang, who gave me useful information and comment for this paper.

\section{REFERENCES}

[1] S. Kim and H. Lee, "The impact of organizational context \& information technology on employee knowledge-sharing capabilities," Public Administration Review, 2006.

[2] V. Kyriakidou, C. Michalakelis, and T. Sphicopoulos, "Assessment of information and communications technology maturity level," Telecommunications Policy, vol. 37, issue 1, 2013.

[3] Q. T. Pham, "Measuring the ICT maturity of SMEs," Journal of Knowledge Management Practice, vol. 11, no.1, 2010.

[4] M. Chesser and W. Skok, "Road-map for successful IT transfer for small businesses," ACM, 2000.

[5] D. Y. Chang, "Applications of the extent analysis method on fuzzy AHP," European Journal of Operational Research, vol. 95, no. 3, pp. 649-655, 1996.

[6] T. L. Saaty, "Decisions with the analytic network process (ANP)," University of Pittsburgh (USA), ISAHP, 1996.

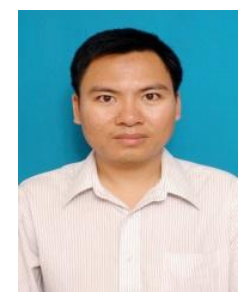

Pham Xuan Kien is with School of Management and Economics, UESTC, Chengdu, China. He's from Ho Chi Minh city, Vietnam. Pham got MIS Masters' degree at HCM City University of Technology, Vietnam. His major is management information system, data mining and his current research interests are MCDM, data mining. Pham is doing his $\mathrm{PhD}$. research in Management Science at University of Electronic Science and Technology of China (UESTC), China. He has published some papers in MCDM in uncertainty and information communication technology measurement.

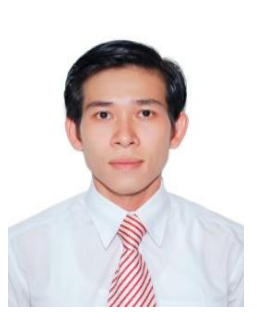

Le Ngoc Son is with School of Management and Economics, UESTC, Chengdu, China. Le's from Ho Chi Minh city, Vietnam. He got Masters' degree of computer science at HCM City University of Technology, Vietnam. Le is a lecturer in IT department of Industrial University of HCM city. Recently, he is researching in information management and data mining. His current research interests are MCDM and CBR. Now he is a PhD. candidate in UESTC. Son has published some papers in new combination of AHP and CBR, and proposed a model for firm's technological capability assessment under fuzzy environment.

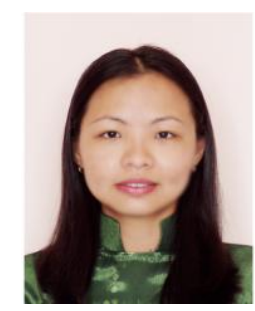

Nguyen Thi Phuong Giang is with School of Management and Economics, UESTC, Chengdu, China. She's from Ho Chi Minh city, Vietnam. Nguyen got Masters' degree of Computer Science at HCM City University of Technology, Vietnam. She is a lecturer in IT department of Industrial University of HCM city. Her current research interests are MCDM. Nguyen is doing his $\mathrm{PhD}$. research in Management Science at UESTC, China. She has published some papers in MCDM and SWOT analysis. 